\title{
Preliminary Report on a Study of Resistivity Structure beneath the Northern Honsyû of Japan
}

\author{
Research Group for Crustal Resistivity Structure, JAPAN*
}

(Received August 15, 1983)

\begin{abstract}
Observations of geomagnetic variations were made at 14 sites in the Northern Honsyû of Japan in 1981. At many sites variations in the electric field were simultaneously recorded. The objective was to investigate the electrical resistivity structure of the island arc, since the Northern Honsyû has various features of a typical island arc.

Variations in the magnetic and the electric field at frequencies from about $10^{-4} \mathrm{~Hz}$ to $17 \mathrm{kHz}$ were observed at some of the stations by use of fluxgate magnetometers as well as induction type ones, although at most of the sites observation covered the frequency range of $10^{-4}$ to $10^{-1} \mathrm{~Hz}$. Examining the transfer function of the geomagnetic variation, it has been revealed that the coast effect is predominant, having unignorable influence on the geomagnetic variations even at such a remote station as $150 \mathrm{~km}$ from the coast of the Pacific. Magnetotelluric soundings suggest that the lower part of the crust is of low resistivity. On the Japan Sea side, a low resistivity layer of $60 \mathrm{ohm} \cdot \mathrm{m}$ appears at a depth of about $20 \mathrm{~km}$, which coincides well with the depth of a seismological boundary, the Conrad disconituity, between the upper and the lower crust.
\end{abstract}

*Research Group for Crustal Resistivity Structure:

Chief investigator:

T. Yukutake, Earthquake Research Institute, University of Tokyo

Co-investigators and participants:

K. Noritomi, T. Nishitani, Mining College, Akita University

S. Nabetani, Department of Earth Sciences, Hirosaki University

A. Takagi, M. Mishina, Aobayama Seismological Observatory, Tohoku University

T. Saito, K. Yumoto, Onagawa Magnetic Observatory, Tohoku University

M. Seto, Y. Kitamura, Tohoku Institute of Technology

M. Kawamura, K. Ochi, Y. Mizuno, T. Tachikawa, S. Fujita, T. Tokumoto, Kakioka Magnetic Ovservatory

H. Mizuno, Geographical Survey Institute

Y. Ono, I. Sato, T. Uchida, Geological Survey of Japan

H. Utada, Y. Sasai, T. Yoshino, S. Koyama, Y. Ishikawa, Earthquake Research Institute, University of Tokyo

N. Sumitomo, Institute of Earch Science, Kyoto University

S. Otsuka, Kobe Gakuin University

J. Miyakoshi, Institute of Earth Science, Tottori University 


\section{Introduction}

In order to investigate the resistivity structure of an island arc, observations of variations in the geomagnetic and the geoelectric field were made with array stations in the Northern Honsyû in 1981 (Fig. 1). The study area is known to be typical of an island arc with the Japan trench to the east where the Pacific plate is supposed to subduct and with the back-arc sea, the Japan Sea, to the west. Active volcanoes are distributed on the back-arc side of the island behind the so called volcanic front that runs through the study area along the island-arc axis. The measured heat flow values are high on the back-arc side, and low on the Pacific side. In view of the varying geothermal character across the island, it was originally surmised that the resistivity structure might be different between the east and the west parts of the study area.

Seismology provides useful data as well. The upper mantle beneath the island is characterized by low value of a $Q$ and low seismic velocity (UTSU, 1971). Explosion seismology (RESEARCH GROUP FOR EXPLOSION SEISMOLOGY, 1977) disclosed a detailed structure of the crust as shown in Fig. 2. The crust consists of two layers with definitely different seismic velocities. The $P$ wave velocity in the upper mantle is significantly smaller beneath the island than beneath the Pacific or beneath the Japan Sea, being consistent with the low $Q$ value. Recent study on the focal depth of microearthquakes has provided basic data to infer mechanical properties of the crust and the upper mantle (TAKAGI et al., 1977). As shown in Fig. 2, most of the earthquatkes occur in the upper crust beneath the island; very few occur in the lower crust. In the upper mantle, seismic foci distribute along the Wadati-Benioff zone forming a double structure. It is also interesting to examine whether or not these features are reflected in the resistivity structure.

The study of the electromagnetic induction has been conducted extensively all over the Japanese islands. There are several places where the geomagnetic variation shows an anomalous behaviour. The most well known is the Central Japan anomaly (RIKITAKE, 1969). For the periods of several minutes to several hours, the vertical component varies in proportion to the variation in the horizontal component. The ratio becomes as large as 0.6 at some places. The anomalous area covers the central part of Honsyû, south of the study area. To the north, there is another anomalous area called Northeastern Japan anomaly (KATO et $a l .$, 1971), where the variation of the vertical component is reversed. This reversed variation of the vertical component is interpreted to be largely due to the concentrated electric currents flowing through the Tugaru strait between Honsyû and Hokkaidô (Yamashita and Yokoyama, 1976). The present study area is located between these cnomalous areas, and characterized by small variation of the vertical component.

In 1970, geomagnetic observations were conducted in almost the same area. Parkinson vectors computed from the magnetic recrods were found to point to the east, normal to the coast line of the Pacific, indicating the existence of the coast effect (SETo et al., 1970). A model study suggested that the observed varia- 


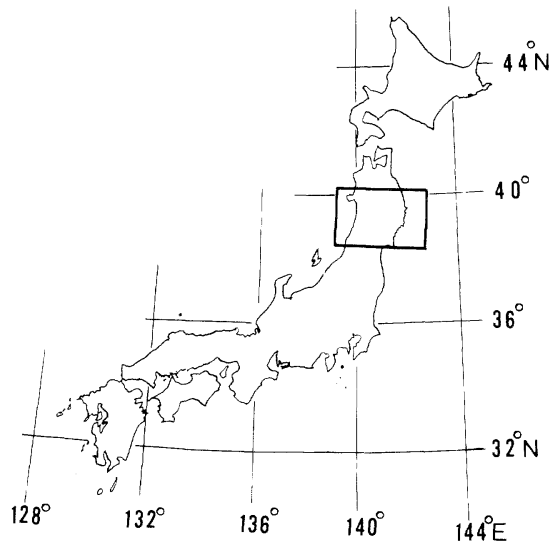

(a)

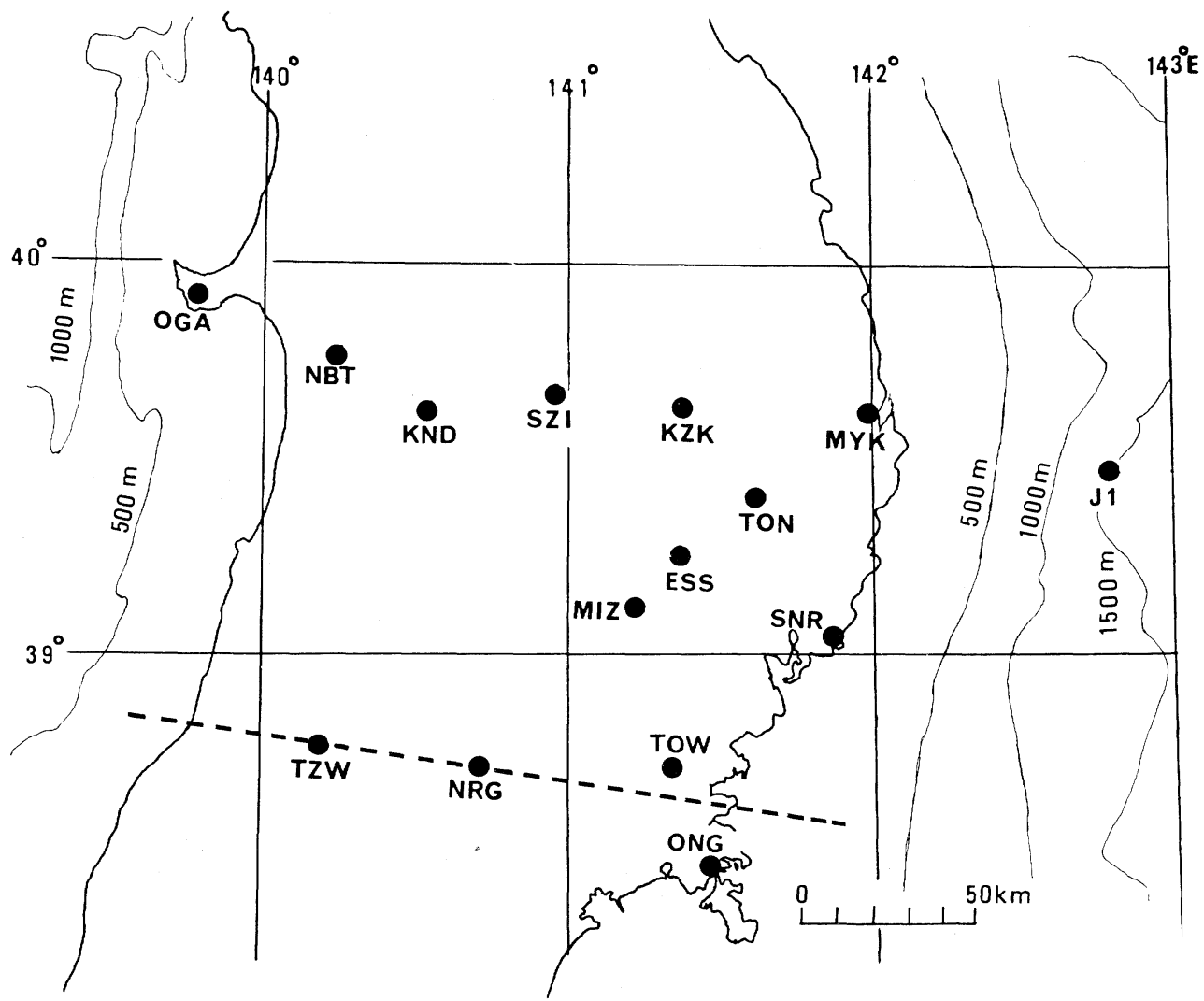

(b)

Fig. 1. Location of observation sites. MIZ and ESS are permanent observation sites of Mizusawa Geodetic Observatory, Geographical Survey Institute, and ONG is the Onagawa Magnetic Observatory of Tohoku University. The dotted line is a survey line of VLF and ELF measurements for a horizontal profiling. 


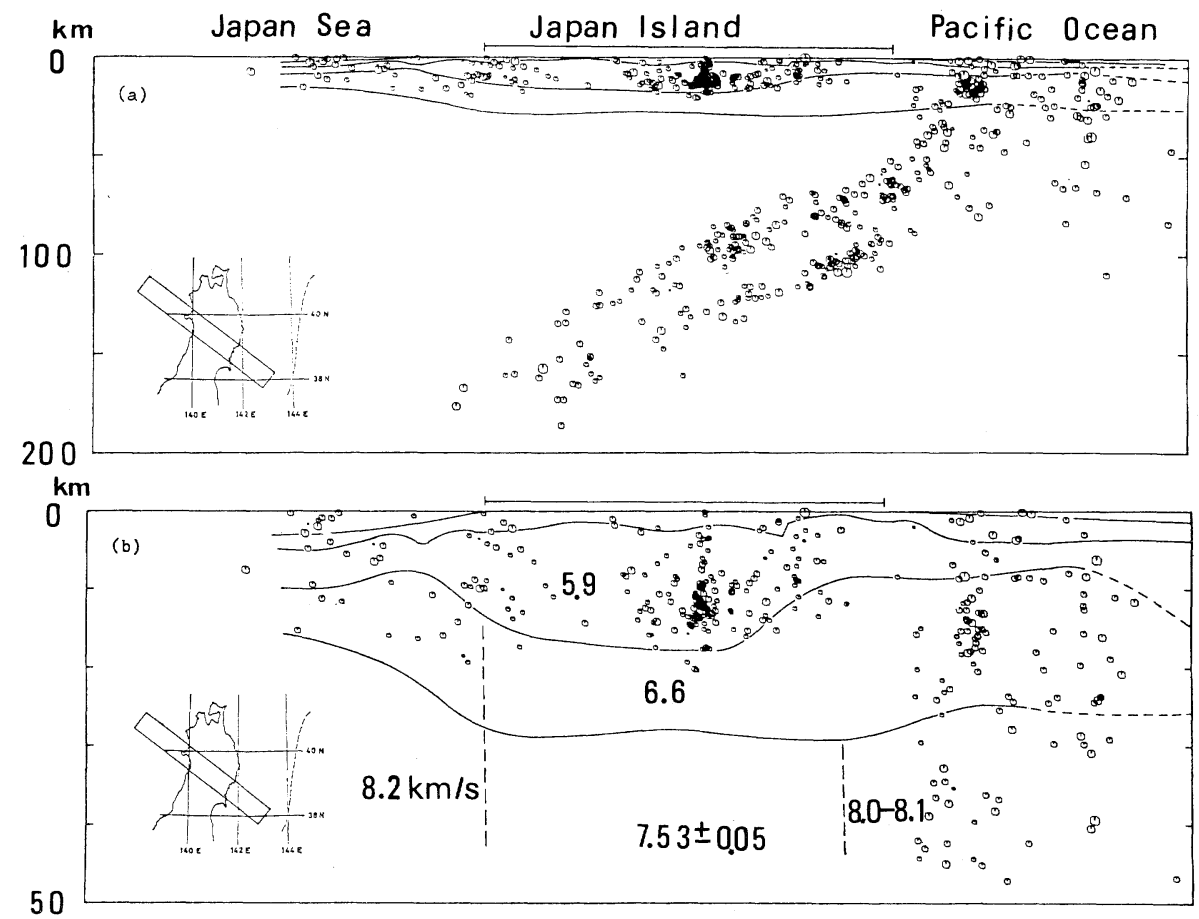

Fig. 2. A profile of seismic foci across the island (TAKAGI et al., 1977). The crustal structure obtained by explosion seismology (RESEARCH GROUP for EXPLOSION SEISMOLOGY, 1977) is shown together. The vertical scale differs between the upper and the lower diagrams. It is noted that the earthquakes occur in the upper crust and that very few occur in the lower crust beneath the island.

tions were explained by a sharp contrast of electrical conductivity between sea and land, without assuming any notable anomalous structure in the crust or the upper mantle (HONKURA, 1974), although there had been suggestions of a deeping of the conducting layer beneath the Pacific and uprising under the island (RikitaKe, 1969; KATo et al., 1971; SATO, 1981).

The present experiment has two new aspects. Firstly the observations were made simultaneously with a sea floor experiment in the west Pacific (YUKUTAKE et al., 1983). This will provide new materials for the investigation of lateral inhomogeneity of the upper mantle structure over the arc-trench system. Secondly, magnetotelluric soundings were made extending the freuency coverage toward higher frequency up to $17.4 \mathrm{kHz}$, whereas existing soundings are based on lower frequencies covering the periods of several minutes to several hours (SATO, 1981). This paper reports the outline of the experiments and preliminary results of the analyses. 


\section{Experiments}

During the period from June to August 1981, fluxgate magnetometers were deployed at the sites shown in Fig. 1 except for TOW and SNR. Among the stations MIZ and ESS are observation sites of Mizusawa Geodetic Observatory of the Geographical Survey Institute, and ONG is that of Onagawa Magnetic Observatory of Tohoku University. Fluxgate magnetometers were installed to observe the relatively low frequency phenomena which cover the period range of several minutes to several hours. At most of these stations variations in the electric field were measured simultaneously.

Induction magnetometers were used to record geomagnetic pulsations with periods of a few tens of seconds. Taking into account the 27 day. recurrence tendency of magnetic disturbances, the observations were made for the period from August 20 to August 26. A magnetic storm took place on August 23 and lasted for 2 days. Pc3 type pulsations were recorded at many stations.

Making use of Schumann resonance, magnetic variations of ELF range (8 to $20 \mathrm{~Hz}$ ) were measured by induction-type magnetometers simultaneously with electric field at the ground surface at the site TZW and NRG. For simplicity we call this type of measurement ELF measurement hereafter. At these two sites, not only the ELF measurements but also the measurement of electromagnetic variations of $17.4 \mathrm{kHz}$ emitted from an artificial source were made with the Geonics EM16R. We call this VLF measurement for its frequency range. Geomagnetic and geoelectric records thus obtained by various instruments provide basic data for the magnetotelluric soundings for a wide range of frequency.

Besides these fixed stations. VLF and ELF measurements were carried out along a survey line shown in Fig. 1 to obtain lateral variations of resistivity. The measurements were intended to give lateral profiles of apparent resistivity at specific frequencies from east to west across the island.

\section{Magnetic Variations}

Simultaneous records of geomagnetic variations obtained by fluxgate magnetometers are shown in Fig. 3, where declination is taken as positive for the variation toward west. The records cover one full day from $22 \mathrm{~h} 00 \mathrm{~m}$ (JST) of July 25 to $22 \mathrm{~h} 00 \mathrm{~m}$ (JST) of July 26. Except for the records for Kakioka and Memanbetsu that are both outside the study area, variations in the vertical component resemble those of the declination for shorter periods such as one hour. This feature is particularly remarkable for the variations at stations MYK (Miyako) and TON (Tono) close to the Pacific coast.

Transfer functions were computed at each station by the equation,

$$
Z=A \cdot H+B \cdot D
$$

where $H, D, Z$ denote horizontal component, declination and vertical component respectively. $D$ is taken positive when it varies toward west. The results are shown 


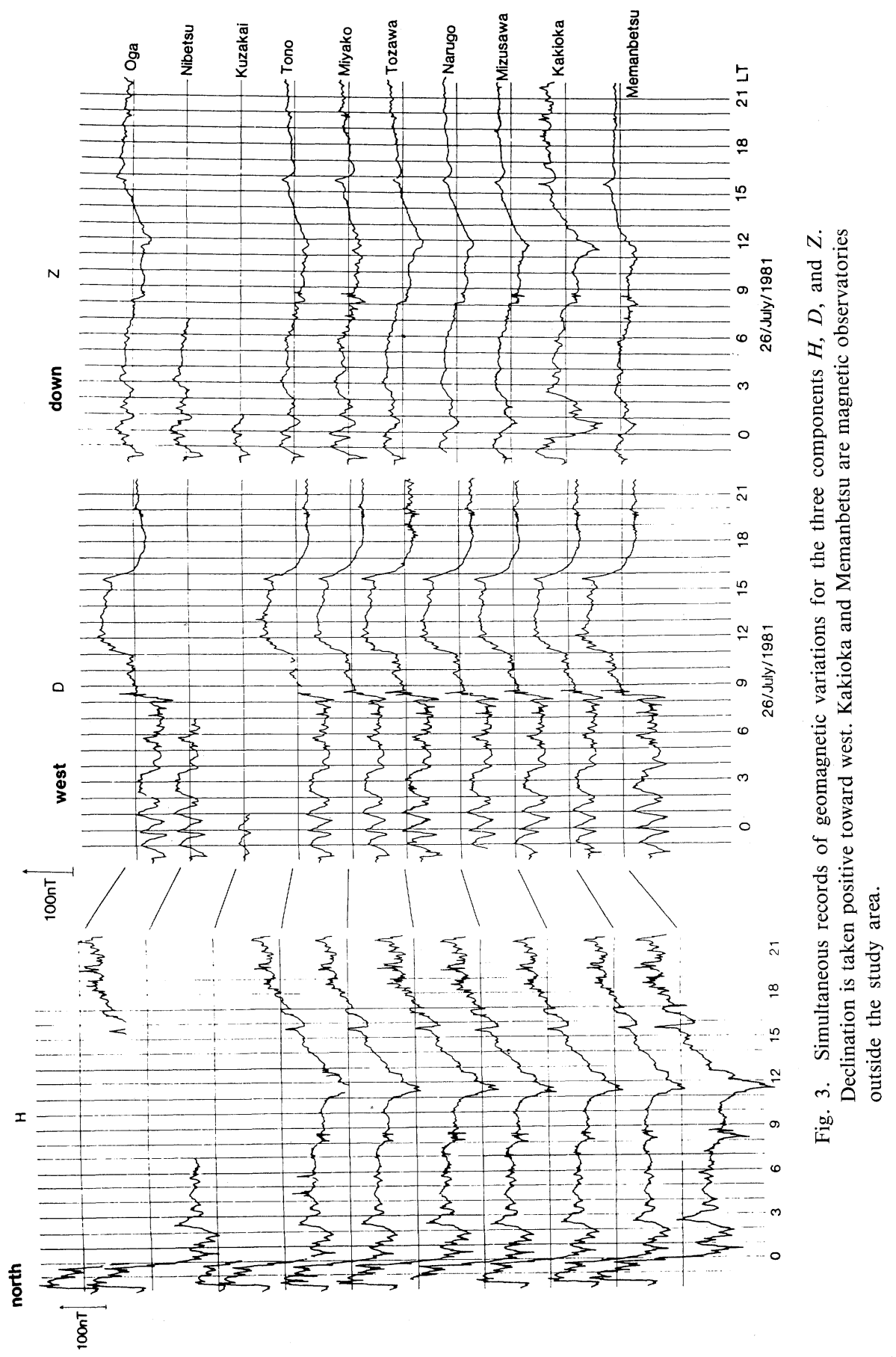


for two stations in Fig. 4. One is the station TON near the east coast, whereas the other is the station NBT close to the Japan Sea. $A_{u}$ and $B_{u}$ represent real parts of $A$ and $B$, while $A_{v}$ and $B_{v}$ represent their imaginary parts. At TON, $B_{u}$ is positive and almost constant 0.3 for the whole period range of analysis, from 5 minutes to 180 minutes. In comparison, $A_{u}$ is small. Imaginary parts $A_{v}$ and $B_{v}$ are both small too. These indicate that at this station the variations
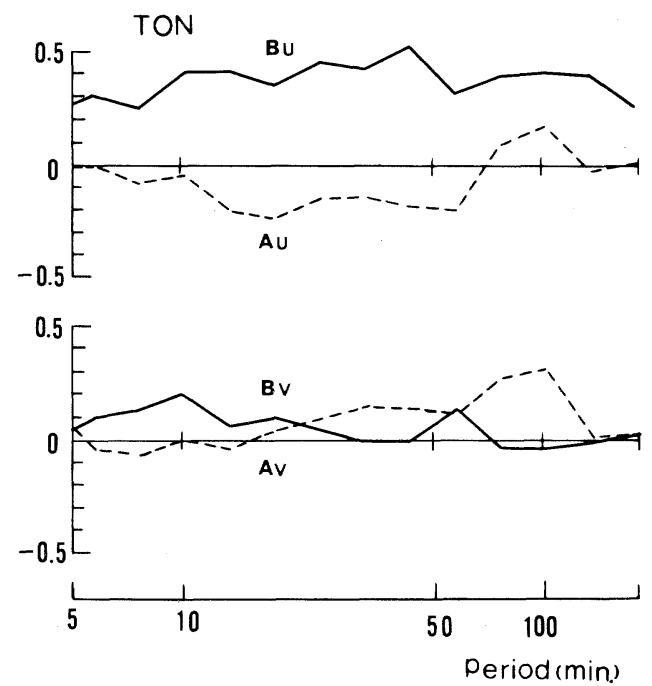

(a)
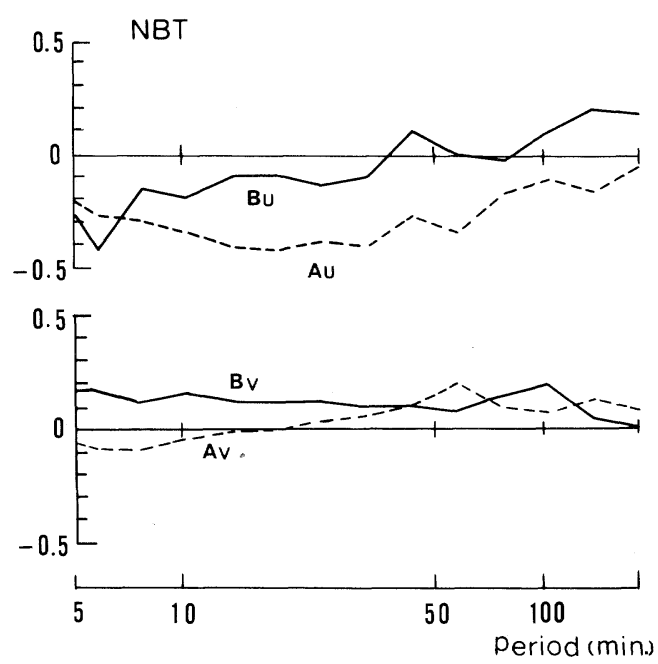

(b)

Fig. 4. Transfer functions at TON and NBT. $A_{u}$ and $B_{u}$ are real parts of $A$ and $B$, while $A_{v}$ and $B_{v}$ are their imaginary parts. 
in the vertical component are highly correlated to those of declination. At NBT, on the other hand, $B_{u}$ changes its sign according as the period, positive for longer periods and negative for shorter periods. This may be interpreted as a result of opposing effects of the coast by the Japan Sea and the Pacific. The shorter period variations are affected by the electric currents induced in the Japan Sea, whereas the longer period variations are influenced by the Pacific coast effect in spite of remoteness of the station from the Pacific coast. On the other hand, $A_{u}$ is negative for all the period. The negative $A_{u}$ indicates that the vertical component is inversely correlated to the horizontal component for the whole period range.

$B_{u}$ is plotted in Fig. 5 for various stations from east to west. At MYK, a station on the Pacific coast, $B_{u}$ is as large as 0.8. It decreases as one proceeds to the west, and becomes more dependent on the period. At OGA, the westernmost station, $B_{u}$ is negative except for the periods longer than 100 minutes. It can be said from this result that the Pacific ocean influences the magnetic variation of longer periods over a distance of $150 \mathrm{~km}$ from the coast. Figure 6 shows $B_{u}$ for the sea floor station $\mathrm{Jl}$ that is located on the slope of the continental shelf at the depth of $1540 \mathrm{~m}$. It is striking that $B_{u}$ exceeds unity for the periods from 10 to 100 minutes. A model study (HonkurA, 1974; Ogawa and Yukutake, 1984, in preparation) indicates that, when the transfer function is computed on the surface of the ocean as well as on the surface of the ground, $B_{u}$ is the largest at the Pacific coast and that it can never exceed 0.6 for 60 minute period. The large value is perhaps a feature characteristic to the sea floor.

Parkinson vectors are drawn in Fig. 7 from $A_{u}$ and $B_{u}$ for the periods of 30 and 57 minutes. Results of previous experiments (SETO et al., 1970; HonKURA, 1974) are also incorporated in this figure. Solid circles are the observation sites of the present experiment, and the open circles are those of experiments conducted in 1970. The vectors for 30 minutes period are very similar to those for 57 minutes.In the eastern half area, the vectors are clearly influenced by the coast effect, pointing to the east, i.e. normal to the coast line of the Pacific. In the northern part of the study area particularly in the northwest, the vectors tend to point to the north. The effect of the Japan Sea is only seen weakly at sites OGA and NBT for 30 minute period. At the southern sites TZW and NRG, the vectors are small, least affected by the coast effect. It is noted that the vector length exceeds unity at the seafloor station Jl. Inspection of the Parkinson vectors leads to the conclusion that the Pacific ocean has a large influence on the geomagnetic variations not only in the major part of the study area on land but also on the sea floor of the continental slope. It is not clear, however, whether the coast effect illustrated by the Parkinson vectors (or the transfer functions) is entirely due to the conductivity contrast between sea water and land or whether it is partly caused by lateral change of resistivity structure in the crust and the upper mantle. 
Preliminary Report on a Study of Resistivity Structure
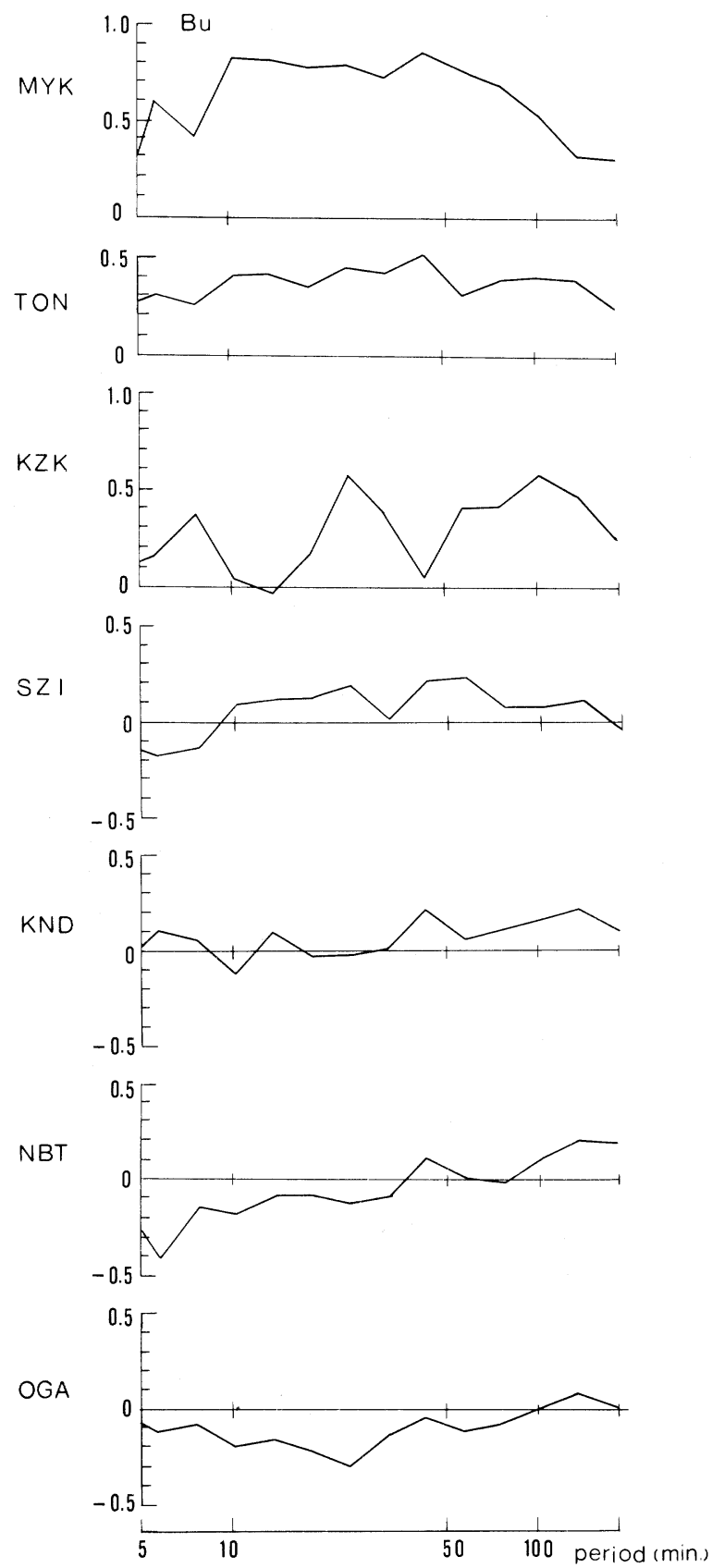

Fig. 5. Transfer function $B_{u}$ for various stations. From the top to the bottom, shown are $B_{u}$ for stations from east to west, i.e. from the Pacific coast to the Japan Sea coast. 


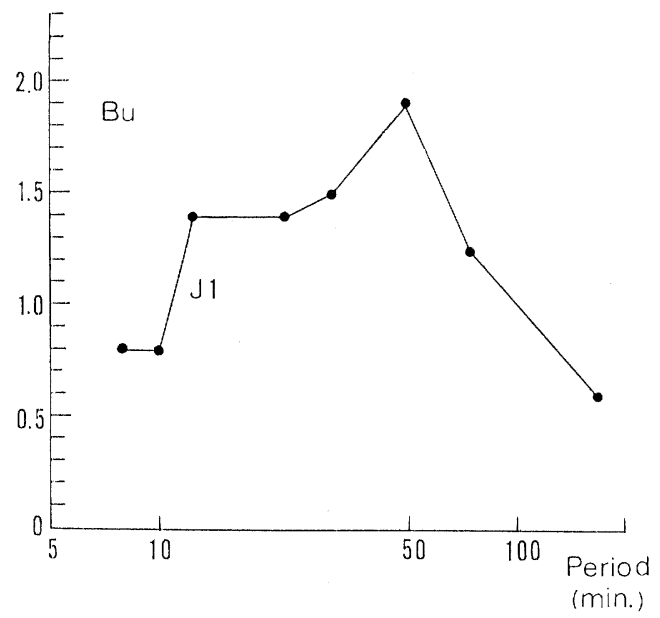

Fig. 6. Transfer function $B_{u}$ for a sea floor station J1.
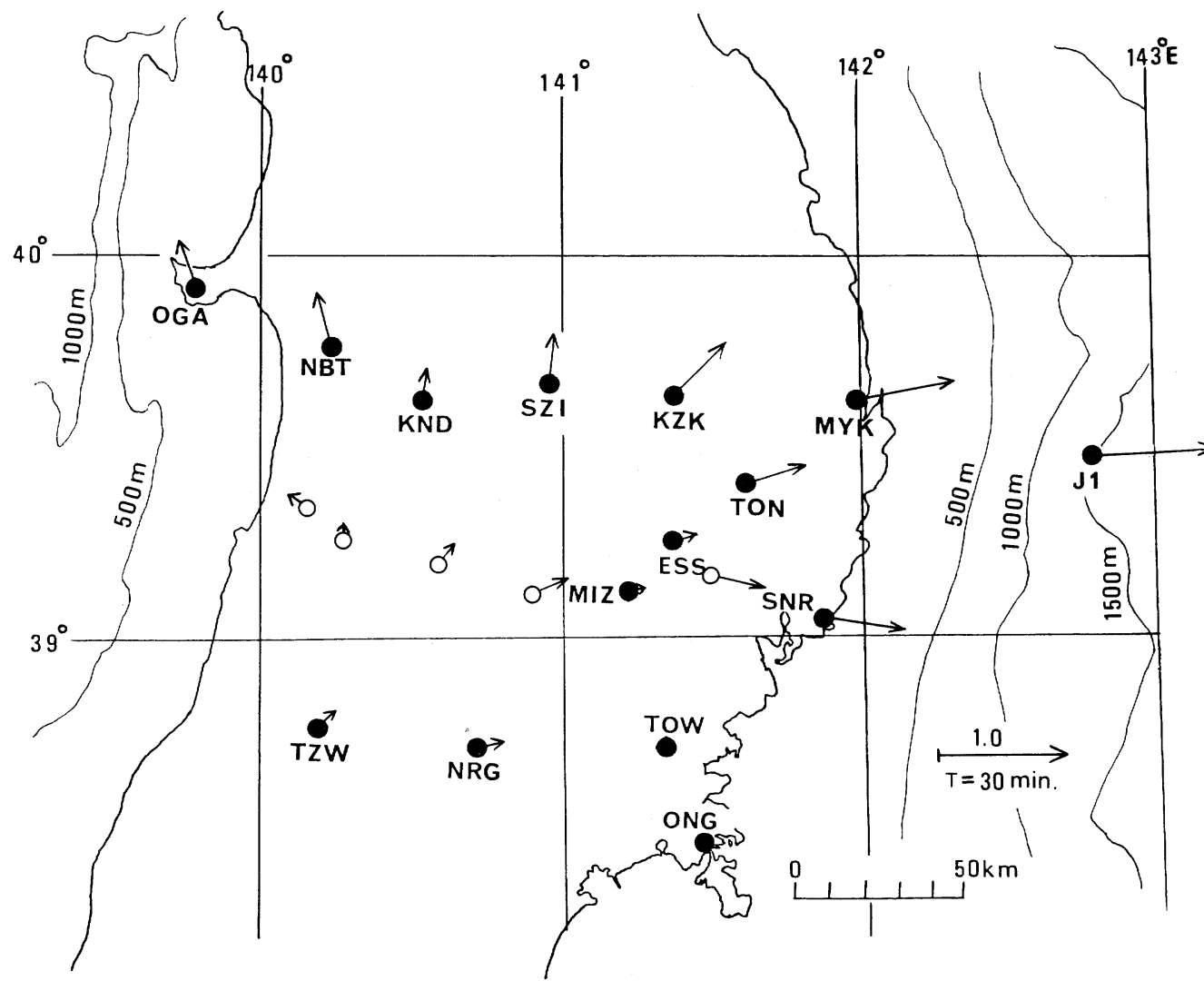

Fig. 7. (a) 


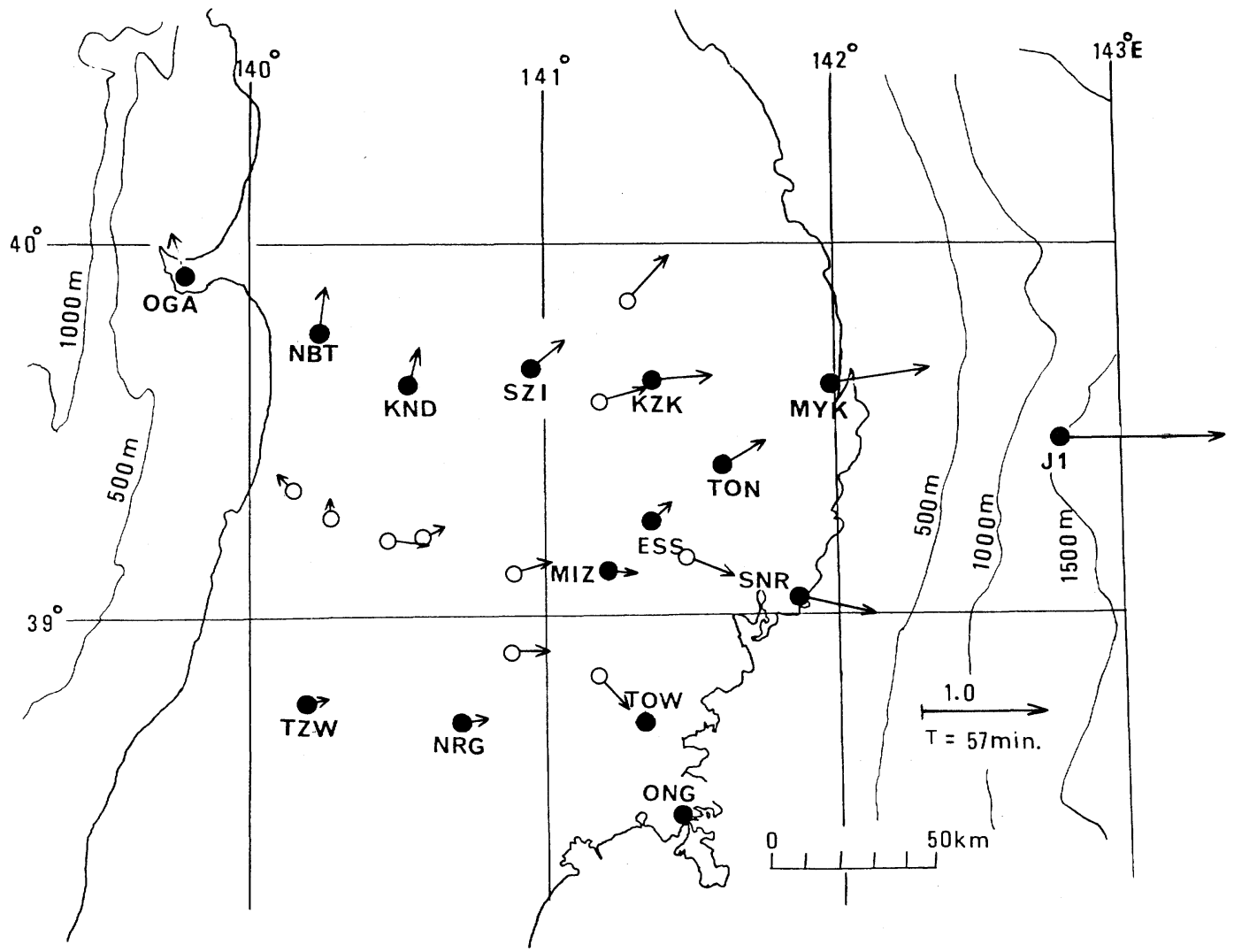

(b)

Fig. 7. Parkinson vectors. Solid circles represent the observation sites of the present experiment, while the open circles those of the previous experiments. At SNR, TOW and ONG, only the geomagnetic pulsations were observed and no records were available for the period range concerned. The parkinson vector drawn for SNR is based on the previous experiments in 1970 .

(a) For $30 \mathrm{~min}$. period. (b) For $57 \mathrm{~min}$. period.

\section{Horizontal Profiling of Apparent Resistivity}

VLF- and ELF- measurements were made across the Northern Honsyû along the dotted line in Fig. 1 (UTADA et al., 1982). Variations in the electric field were measured simultaneously with those of the magnetic field. Apparent rsistivity was computed from the ratio of the electric to the magnetic variations of mutually orthogonal component. As for VLF measurement $(17.4 \mathrm{kHz})$, measured were the horizontal component of the electric field in the direction of the wave propagation on the ground surface and the horizontal component of the magnetic field normal to its direction. As for ELF measurement ( 8 to $20 \mathrm{~Hz}$ ), two sets 
of electric and magnetic variations were measured, the electric north and magnetic east component and the electric east and magnetic north component. Due to lateral inhomogeneity of geological structure, two sets of data do not necessarily give consistent results. Only the data sets that do not yield remarkable anisotropy of electric variations were used to compute the resistivity, mostly with the skewness less than 0.2 , exceptionally with 0.5 at most.

Apparent resistivities thus obtained for $8 \mathrm{~Hz}$ and $17.4 \mathrm{kHz}$ are shown in Fig. 8. The two profiles are fairly consistent, reflecting the surface topography as high resistivity in the mountain areas such as Kitakami, Oou and Dewa mountains and low resistivity in the plains. Measurements of $17.4 \mathrm{kHz}$ give apparent resistivities systematically higher than those of $8 \mathrm{~Hz}$. This stems from difference in the penetration depth for these frequencies. For the homogeneous earth of $100 \mathrm{ohm} \cdot \mathrm{m}$, which is approximately a mean apparent resistivity for $17.4 \mathrm{kHz}$, the skin depth is estimated to be $38 \mathrm{~m}$. For $8 \mathrm{~Hz}$, on the other hand, the mean resistivity being approximately $20 \mathrm{ohm} \cdot \mathrm{m}$, the skin depth becomes about 796

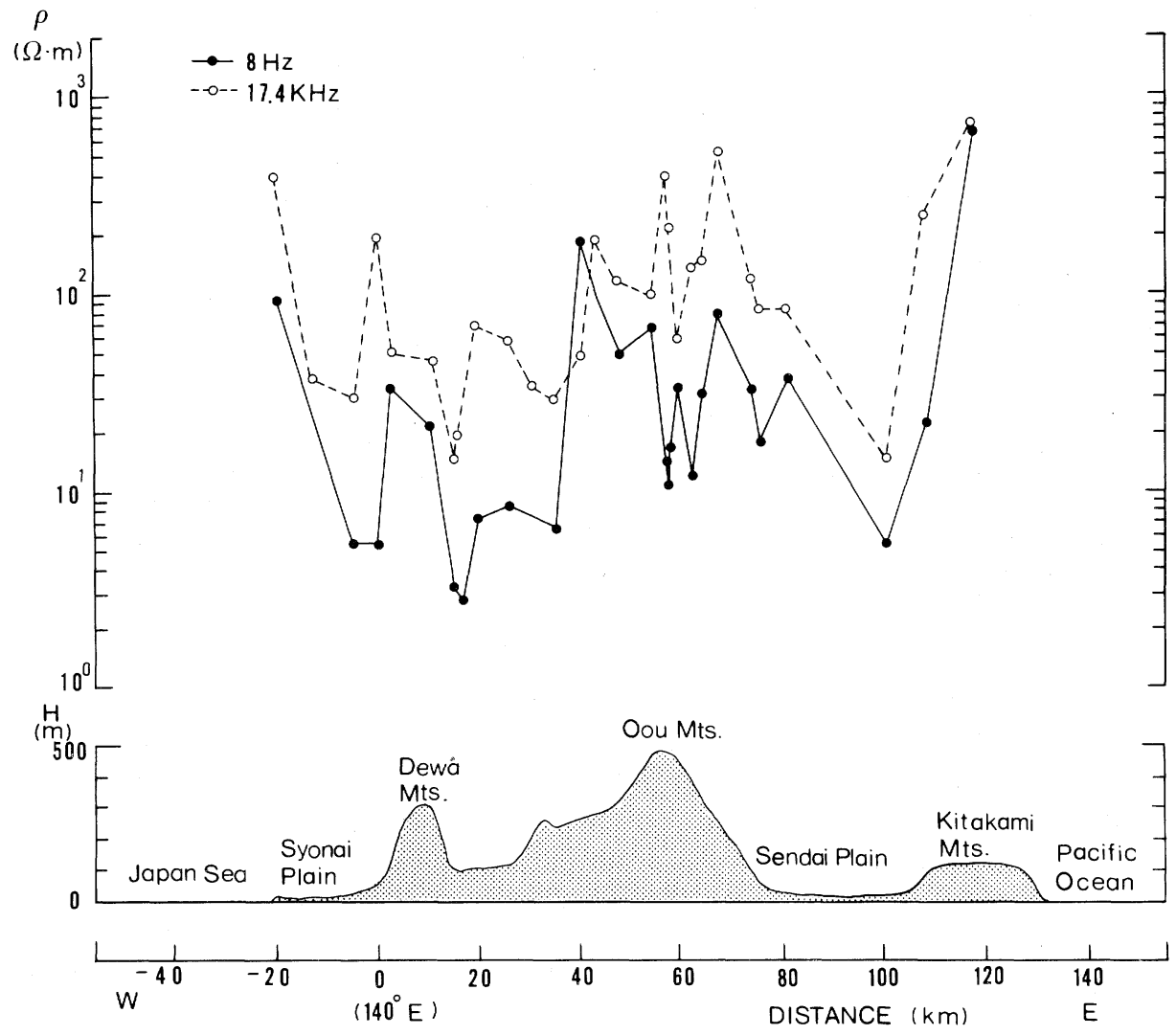

Fig. 8. Apparent resistivity across the Northern Honsyû for $8 \mathrm{~Hz}$ and $17.4 \mathrm{kHz}$. 
m. The difference in the apparent resistivity shown in Fig. 8 indicates that the resistivity near the surface is generally higher than that at depths of several hundred meters.

\section{Magnetotelluric Soundings}

For the frequency range from about $10^{-4} \mathrm{~Hz}$ to $17.4 \mathrm{kHz}$, magnetotelluric analyses were made of the data at three sites, TZW, NRG and ESS. At TZW anisotropy of electric field variations is small. The skewness of impedance is about 0.2. This is consistent with the small size of the Parkinson vectors discussed in a previous section. Apparent resistivity and phase difference between the electric and the magnetic variations are shown in Fig. 9 for the east component of the electric $\left(E_{y}\right)$ and the north component of the magnetic field $\left(H_{x}\right)$. The apparent resistivity becomes a minimum at an ELF range, about $10 \mathrm{~Hz}$, and a maximum at a pulsation range with frequency about $10^{-1} \mathrm{~Hz}$. Assuming that the earth consists of five layers, resistivity and thickness of each layer were determined so as to fit best to the observed apparent resistivities and phase differences. Resistivity of the shallower part is low $(2-15 \mathrm{ohm} \cdot \mathrm{m})$, and decreases to the depth of $800 \mathrm{~m}$. At the depth, a resistive layer of $6000 \mathrm{ohm} \cdot \mathrm{m}$ appears. This seems to suggest that the sedimentary layer of low resistivity covers the surface down to this depth. A layer of high resistivity $(6000 \mathrm{ohm} \cdot \mathrm{m})$ continues to the depth of $18 \mathrm{~km}$, then a low resistivity layer of $60 \mathrm{ohm} \cdot \mathrm{m}$ appears. From the model apparent resistivity and phase difference were computed as depicted by solid lines in Fig. 9 (a). It should be noted that the low resistivity layer appears at the depth of $18 \mathrm{~km}$, which agrees well with the boundary between the upper and the lower crust in this area determined from explosion seismology.

At NRG, a strong anisotropic behaviour of the electric field was found for the frequency range of $10^{-4}$ to $10^{-3} \mathrm{~Hz}$, corresponding to the period range of 3 to 14 hours. Variations of the north component were remarkably larger than the east component, whereas no conspicuous anisotropy was observed with the electric variations of ELF and ULF-pulsation range. This suggests that, although the structute is homogeneous near the surface, it is highly anisotropic at depths. It is suspectd that concentrated electric currents flow at depths in the north-south direction. Since the north component of the electric field is likely to be contaminated by a certain unknown effect like a channeling effect, the combination of the east component of the electric field with the north component of the magnetic field $\left(E_{y} / H_{x}\right)$ was used for the magnetotelluric soundings. Apparent resistivities and phase differences obtained from this data set are plotted in Fig. 10 (a). A maximum of apparent resistivity appears at ULF range, i.e. for the magnetic pulsations. For the frequency range lower than $10^{-3} \mathrm{~Hz}$, a tendency is clearly seen that the apparent resistivity increases with decrease of frequency. This suggests an increase of resistivity with depth in the deeper parts. Similar to the analysis for TZW, a five layer model was determined and is shown in Fig. 10 (b). Low resistive layers cover the surface down to about $1 \mathrm{~km}$ depth. 

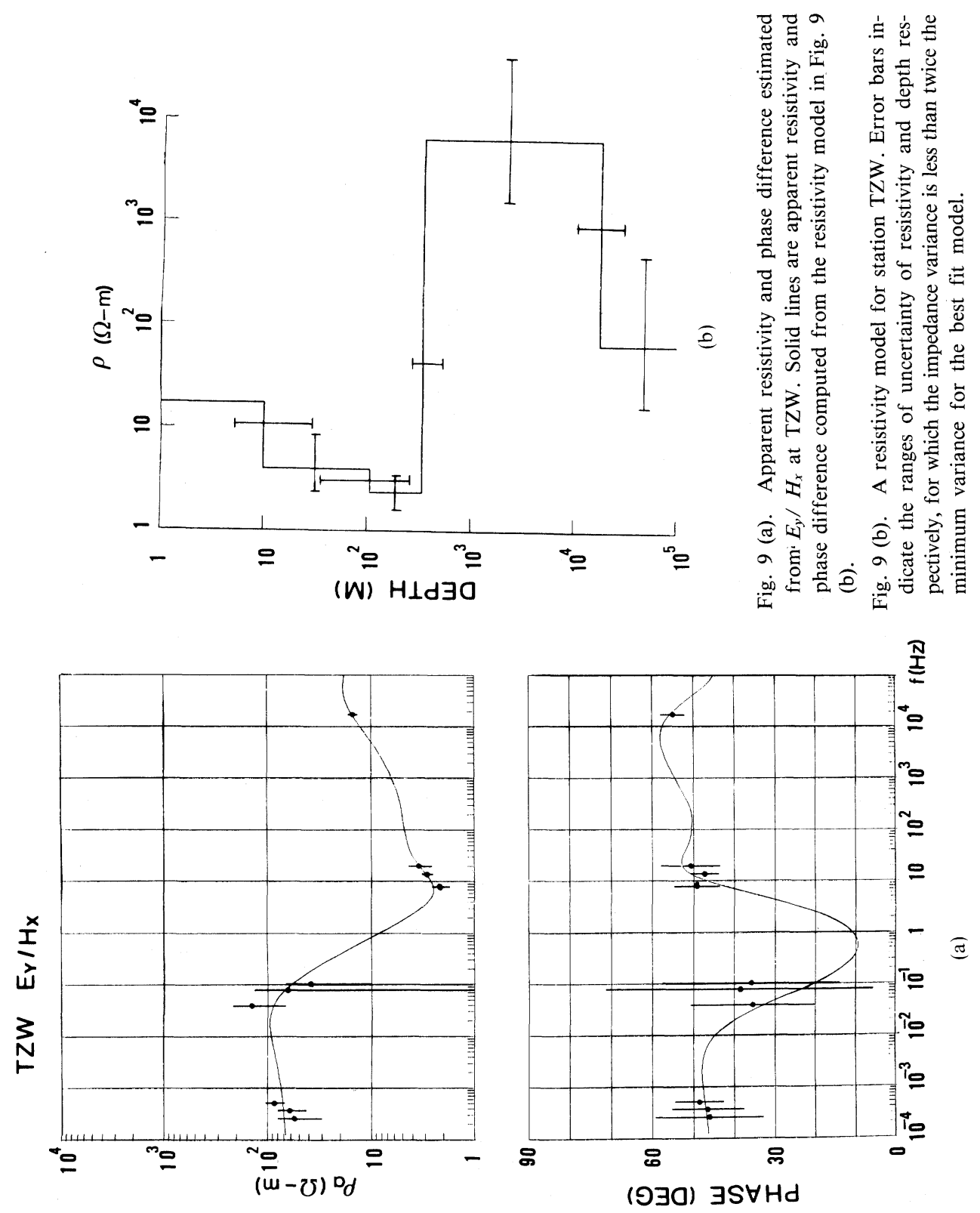

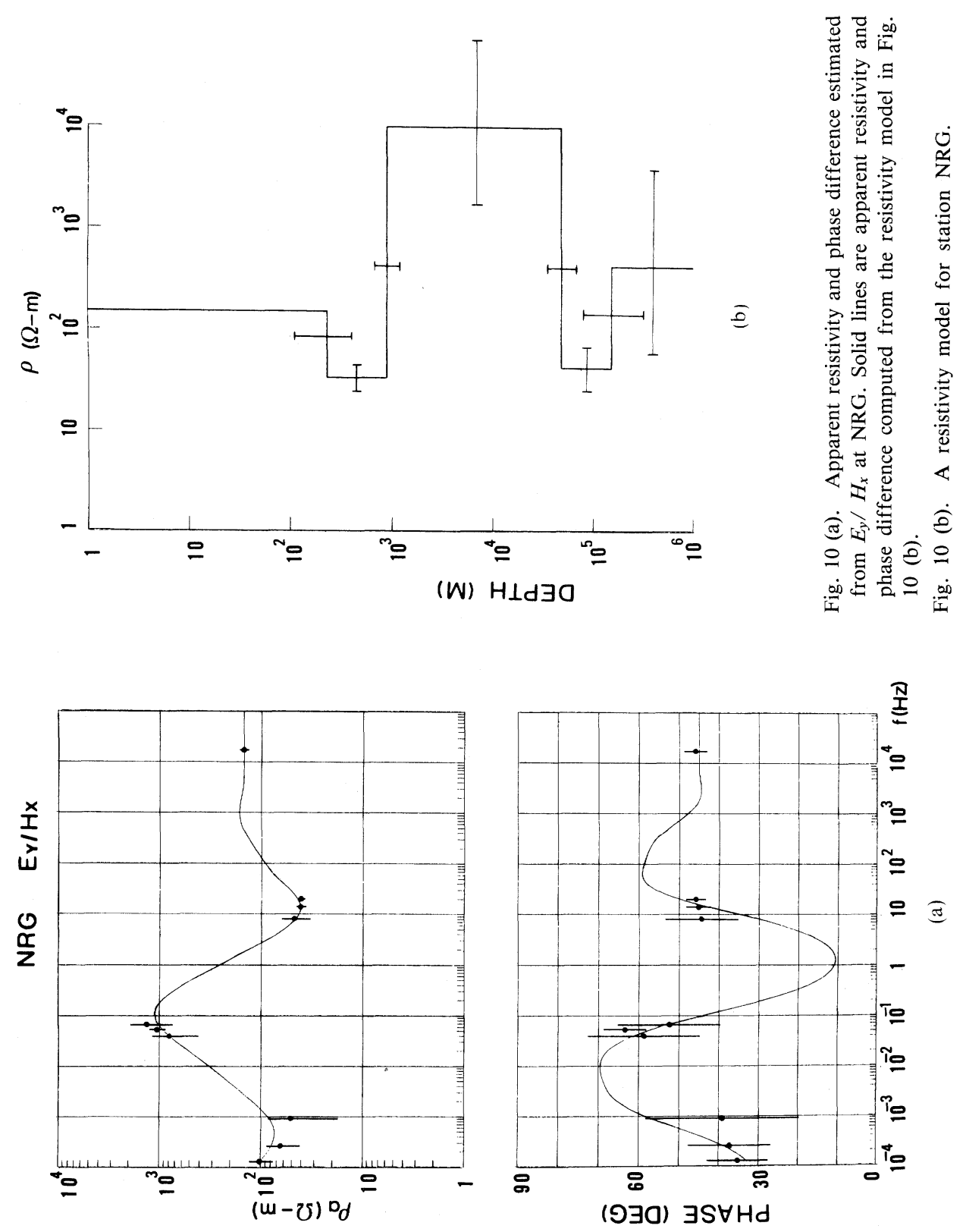


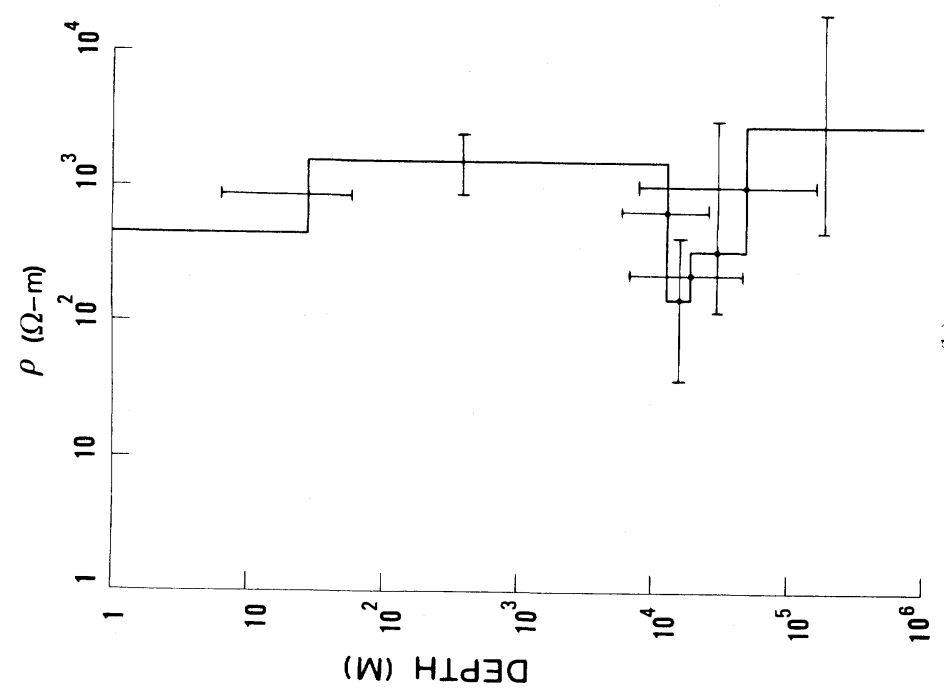

总 $\vec{\sigma}$

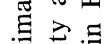

过

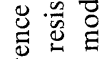

焉焉

这计

㺃

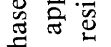

릉

密

(2)

2

म

चี ज्ञ

卷

ए ए

क्षै

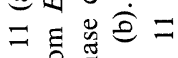

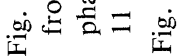
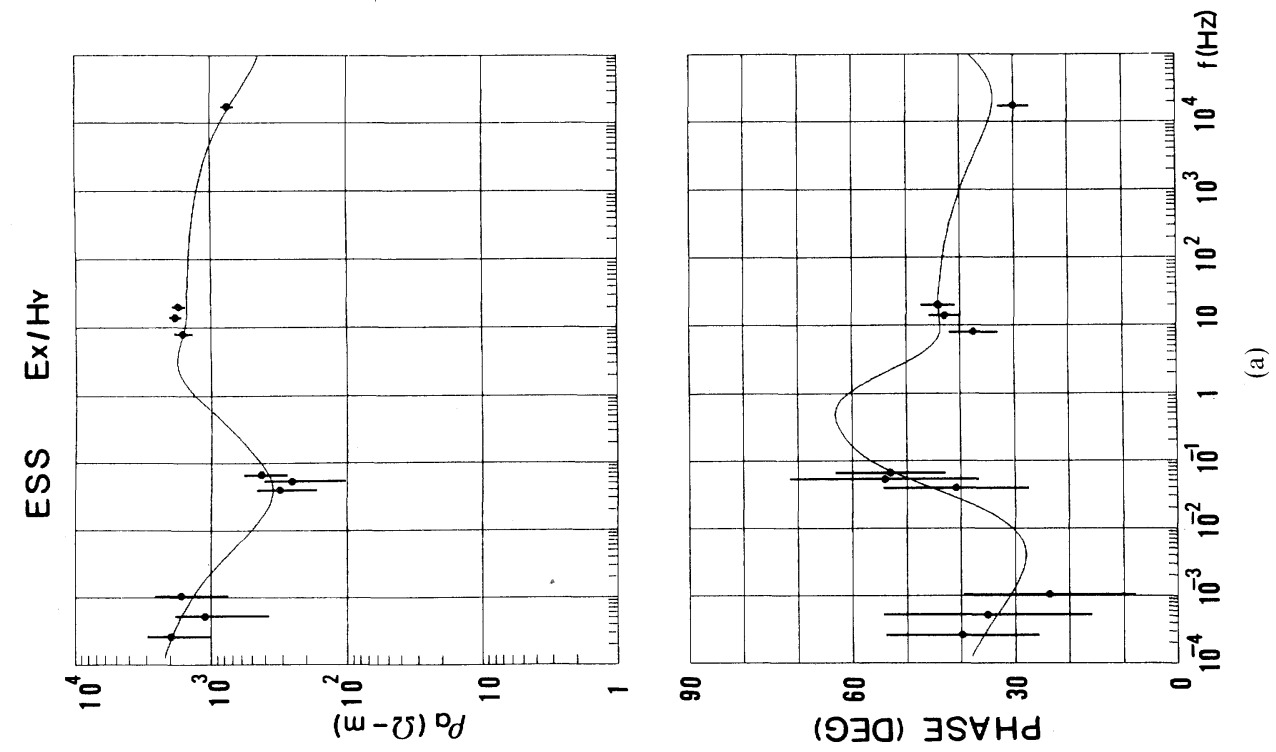
A highly resistive layer of about $10 \mathrm{kilo-ohm} \cdot \mathrm{m}$ underlines them down to a depth of $50 \mathrm{~km}$. Below it a low resistive layer of $40 \mathrm{ohm} \cdot \mathrm{m}$ exists. At a depth of $150 \mathrm{~km}$ another high resistive layer appears again.

At ESS measurements were made for the range of frequency lower than $10^{-1} \mathrm{~Hz}$, but neither ELF nor VLF measurements. For these high frequencies, the data obtained for the horizontal profiling near ESS in the same Kitakami mountain area were used together. The results are shown in Fig. 11 (a) in a way similar to other stations. Apparent resistivity is higher for the VLF and ELF ranges than for the ULF range $\left(10^{-2}-10^{-1} \mathrm{~Hz}\right)$ suggesting that the surface part is more resistive than the deeper part. For the frequency lower than $10^{-3}$ $\mathrm{Hz}$, the apparent resistivity becomes conspicuously higher than that for the frequency of $10^{-3} \sim 10^{-2} \mathrm{~Hz}$. This indicates the existence of a resistive layer in the deeper parts. A five layer model was determined, and shown in Fig. 11(b). The surface part is resistive down to a depth of $12 \mathrm{~km}$ with resistivity of 600 to $1600 \mathrm{ohm} \cdot \mathrm{m}$. The low resistivity layer appears at the depth of $12 \mathrm{~km}$ at this site. The deep resistive layer begins at a depth of about $60 \mathrm{~km}$.

\section{Discussion on Resistivity Structure}

Vertical resistivity profiles at the three sites are reproduced in Fig. 12 in a rather schematic way, with the vertical axis on a linear scale. The surface low resistive layer, which is supposed to be a sedimentary layer, is so thin, less than $1 \mathrm{~km}$, that it is unrecognizable in this diagram. Beneath the surface thin layer, there exists a resistive layer at all the sites. A conducting layer underlies this resistive layer, starting at depths of $20 \mathrm{~km}$ at TZW, $10 \mathrm{~km}$ at ESS and $50 \mathrm{~km}$ at NRG. Another resistive layer appears in the deeper part at depths of $60 \mathrm{~km}$ beneath ESS and $150 \mathrm{~km}$ beneath NRG.

Since the thickness of the crust is about $30 \mathrm{~km}$ in this area (see Fig. 2), the low resistivity layer is definitely within the crust except at NRG where the electric variations are strongly polarized in the north-south direction for the low frequencies. One of the possible causes of low electrical resistivity of the rock is temperature. The Japan Sea side of this area is characterized by high heat flow values. Temperature below the Japan Sea side is considered high in comparison with the Pacific side. The low resistivity layer at first appeared to be explained by the thermal structure. However, from the geothermal gradient in this area, the depth to the $1000^{\circ} \mathrm{C}$ isotherm was estimated to be about $60 \mathrm{~km}$ on the Japan Sea side of the study area (WATANABE, 1968). This is far deeper than the estimated depths of the low resistivity layer. Besides, the low resistivity layer appears at the depth of $10 \mathrm{~km}$ below ESS near the Pacific, where the heat flow is low and the crust is supposed to be cold. It seems, therefore, difficult to ascribe the cause of low resistivity to temperature in the crust.

As was mentioned before, the depth to the low resistive layer beneath TZW and ESS coincides with that of the Conrad discontinuity that divides the crust into the upper and the lower parts. The present study strongly suggests that 


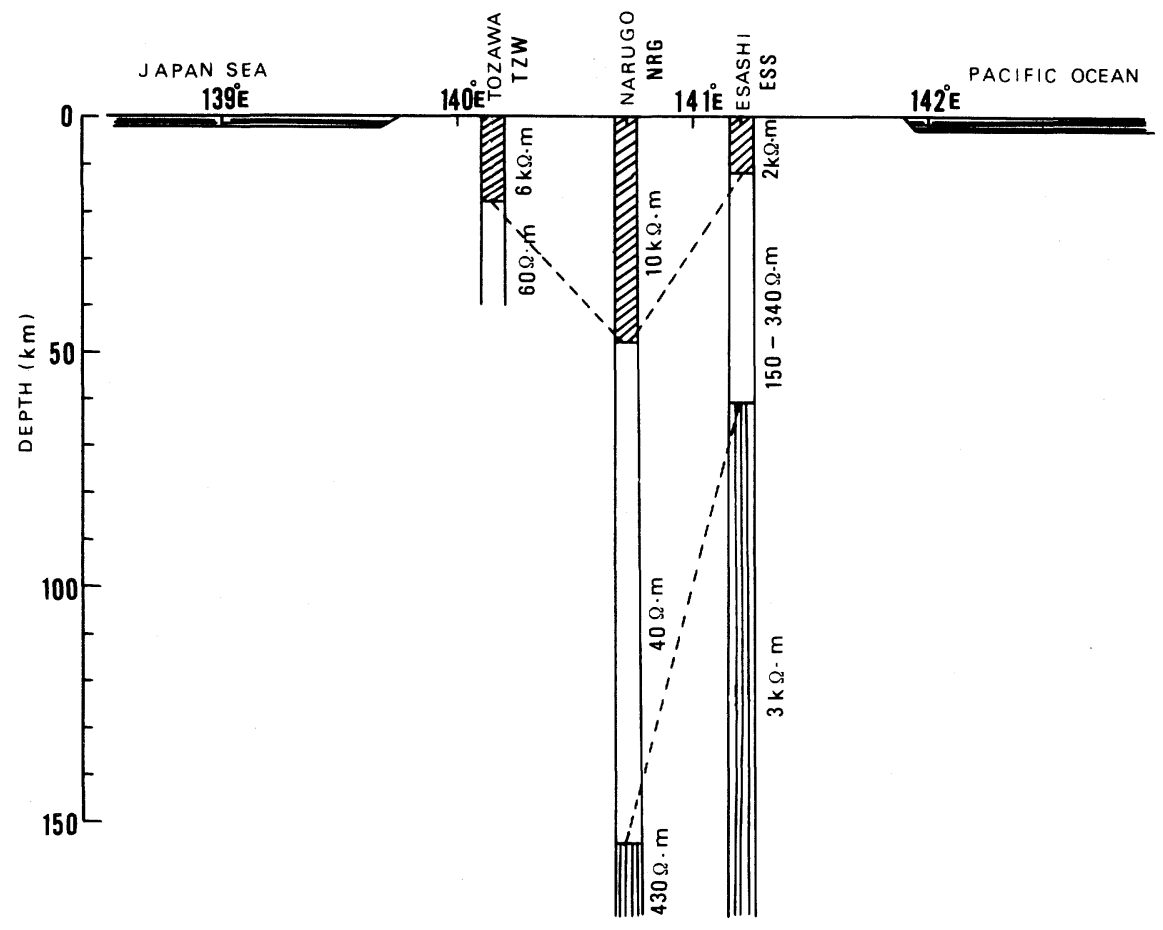

Fig. 12. Schematic diagram of resistivity structure across the Northern Honsyû.

the lower crust is of low resistivity. It is known that the lower crust in this area has mechanical property remarkably different from the upper one. As illustrated in Fig. 2, most of the shallow earthquakes occur in the upper part, and very few in the lower crust. It is not known as yet what causes this difference. However, since the resistivity is highly dependent on the water content of rocks, it is tempted to ascribe its cause to the amount of water contained in the crust, although this is highly speculative.

It is known that, beneath the eastern part of the study area, the Pacific plate subdusts, reaching a depth of about $70 \mathrm{~km}$. It is also known from the magnetotelluric soundings on the sea floor that the resistivity of the plate is high. It seems more than coincidence that a highly resistive layer appears at this depth, although resolution of the depth in the present analysis is not sufficient to draw a definite conclusion on this problem.

\section{Concluding Remarks}

From the geomagnetic observations conducted in the Nortern Honsyû from the Pacific to the coast of the Japan Sea, the variations in the vertical component 
were found to be highly coherent with those in the declination for such longer periods as 60 minutes. The coefficient $B_{u}$ of the transfer function was obtained to become large on the Pacific side and to decrease systematically toward the Japan Sea coast. The $B_{u}$ value was particularly large on the sea floor of the continental slope of the Pacific. All these indicate that the Pacific is greatly influential on the geomagnetic variation in the study area, and that the effect of the Japan Sea is very small. This may be caused primarily by the sharp contrast in the conductivity between land and sea water. However, the effect of the Pacific seems too large for the effect of the sea water alone, whereas the effect of the Japan Sea seems too small. Geomagnetic variations are supposed to be influenced partly by the underground structure, but further analyses are needed to separate its effect from that of the sea coast.

Magnetotelluric analyses have provided more information on the structure of the crust and the mantle. It has been revealed that a low resistivity layer appears at a shallow depth of 10 to $20 \mathrm{~km}$, coincident with the Conrad discontinuity. It is known in this area that many earthquakes take place in the upper crust, whereas very few occur in the lower crust. The mechanical property is supposed to be different between the upper and the lower crust. The present study suggests that the lower crust differs from the upper one not only in the mechanical property but also in the electrical property. Another interesting result obtained in this study is the existence of a highly resistive layer at a depth of 60 to $150 \mathrm{~km}$ near the Pacific, which may possibly be related to the subducting plate beneath the island arc.

\section{REFERENCES}

HONKURA, Y., Electrical conductivity anomalies beneath the Japan arc, J. Geomag. Geoelectr., 26, 147-171, 1974.

Kato, Y., M. Daguchi, M. Seto, and T. ARUGA, Northeastern Japan anomaly of the upper mantle, Science Rep. Tohoku Univ., Ser. 5, Geophys., 21, 19-35, 1971.

RESEARCH GRUP FOR EXPLOSION SEISMOLOGY, Regionality of upper mantle around Northeastern Japan as derived from explosion seismic observations and its seismological implications, Tectonophysics, 37, 117-130, 1977.

RIKITAKE, T., The undulation of an electrically conductive layer beneath the islands of Japan, Tectonophysics, 7, 257-264, 1969.

SATO, S., Upper mantle conductive structures in North eastern Japan from magneto-telluric data, Butsuri-Tanko (Geophys, Explor:), 34, 56-68, 1981.

SETO, T., M. TANAKA, and M. TAZIMA, Observation of magnetic variations near the Mizusawa Geodetic Observatory (I), J. Geod. Soc. Japan, 16, 34-39, 1970.

TAKAgi, A., A. HASEgAwA, and N. UMino, Seismic activity in the Northeastern Japan Arc, $J$. Phys. Earth. 25, S95-S104, 1977.

Utada, H., S. Koyama, Y. SASAI, and T. Yoshino, Resistivity structure of the crust in the Northeastern Japan by ELF. VLF-magnetotelluric methods, Proc. Conductivity Anomaly Workshop 1982, Earthq. Res. Inst. Univ. Tokyo, 21-27, 1982.

UTSU, T., Seismological evidence for the anomalous structure of island arcs with special reference to the Japanese region, Rev. Geophys, Space Phys., 9, 839-890, 1971. 
Watanabe, T., Temperature profiles across the continental margin, Proc. Conductivity Anomaly Symposium, Earthq. Res. Inst., Univ. Tokyo, 167-182, 1968.

YAMASHITA, H. and I. YOKOYAMA, Interpretation of the "Northeastern Japan Anomaly" in electrical conductivtiy of the upper mantle, J. Geomag. Geoelectr., 28, 329-332, 1976.

Yukutake, T., J. H. FillouX, J. Segawa, Y. Hamano, and H. Utada, Preliminary report on a magnetotelluric array study in the North-west Pacific, J. Geomag. Geoelectr., 35, 1983. 